\title{
A Scoping Review of Non-Medical and Extra-Medical Use of Non-Steroidal Anti-Inflammatory Drugs (NSAIDs)
}

\author{
Rebekah Brennan ${ }^{1} \cdot$ Mayyada Wazaify $^{2} \cdot$ Haneen Shawabkeh $^{2} \cdot \operatorname{lan}$ Boardley $^{3} \cdot \operatorname{Jim~McVeigh}^{4} \cdot$ Marie Claire Van Hout $^{5}$
}

Accepted: 26 May 2021 / Published online: 30 July 2021

(c) The Author(s) 2021

\begin{abstract}
Non-steroidal anti-inflammatory drugs (NSAIDs) are among the most commonly used medications worldwide and have analgesic, antipyretic and anti-inflammatory properties. Although NSAIDs are recognised as generally safe and effective, non-medical and extra-medical use of these products can occur. Unlike the use of illegal and many prescription drugs, which are subject to extensive research attention, inappropriate use of NSAIDs has been less well investigated. This scoping review collates and describes what is known regarding non-medical and extra-medical use of NSAIDs. In total, 72 studies were included in this scoping review. Three themes emerged from the review: (1) indicative profile of people who engage in non-medical or extra-medical use of NSAIDs; (2) antecedents for non-medical or extra-medical use; and (3) adverse health effects of non-medical and extra-medical use of NSAIDs. The review concluded that there is a need for enhanced patient education, including among sports people; pharmacovigilance in terms of clinician recognition of aberrance; and prescriber and pharmacist awareness of the potential for extra-medical and non-medical use and the related health harms.
\end{abstract}

\section{Key Points}

Non-/extra-medical use of NSAIDs has increased over time.

Excessive use of NSAIDs amongst elite and non-elite athletes was found to be common and likely to be medically unjustified.

NSAID use amongst the general population was found to be largely unsupervised and with limited awareness for potential harms to many organ systems.

Rebekah Brennan

rebekah.brennan@ucc.ie

1 School of Applied Social Studies, University College Cork, Cork, Ireland

2 Department of Biopharmaceutics and Clinical Pharmacy, School of Pharmacy, The University of Jordan, Amman, Jordan

3 School of Sport, Exercise and Rehabilitation Sciences, University of Birmingham, Edgbaston, Birmingham, UK

4 Substance Use \& Associated Behaviours, Department of Sociology, Manchester Metropolitan University, Manchester, UK

5 Faculty of Health, Public Health Institute, Liverpool John Moore's University, Liverpool, UK

\section{Introduction}

Non-steroidal anti-inflammatory drugs (NSAIDs) are among the most commonly used medications worldwide and have analgesic, antipyretic and anti-inflammatory properties [1]. The global NSAID market size in 2019 was \$US15.58 billion and is projected to reach \$US24.35 billion by 2027 [2]. Because of their general safety and effectiveness, many NSAIDs (e.g. ibuprofen, aspirin) can be bought over the counter (OTC) in different countries. However, stronger doses of some of these drugs, as well as other NSAIDs (e.g. diclofenac, mefenamic acid, naproxen), are only available by prescription [3]. NSAIDs are reported to be safe and effective if used within medical guidelines. However, inappropriate use has also been reported in the literature [4-8]. This can result in a broad spectrum of harms, including gastrotoxicity, hepatoxicity, nephrotoxicity, cardiotoxicity, overdose and even death $[9,10]$, and increases the burden on healthcare systems.

There is a need for enhanced patient education, pharmacovigilance and prescriber and pharmacist awareness in terms of non- and extra-medical use of NSAIDs and the related health harms.

Anecdotal reports, as well as several case reports and mini reviews, have highlighted the trend of extra-medical (using more than prescribed or recommended, for a medical reason) or non-medical (using for reasons other than 
medical, such as to intoxicate) use of NSAIDs $[5,8,11,12]$. This inappropriate use of NSAIDs has increased in recent times, perhaps attributable to the self-care revolution [27], the increasing number and accessibility of medicines and the wide availability of online health information [13].

There have been reports of non-medical use of NSAIDs among athletes who use NSAIDs before exercise as pain prophylaxis to increase their stamina and extend their workout hours [14-16], and early warning reports highlighted other forms of non-medical use amongst the general population [17-20]. Some reports documented intoxicating effects [12], either alone [11] or in combination with illicit drugs [21]. Moreover, the fifth edition of the Diagnostic and Statistical Manual of Mental Disorders (DSM-5) included a specific mention, for the first time, of NSAID use disorder in the "other (or unknown) substance use disorders" subcategory, along with drugs such as anabolic steroids and antihistamines.

Unlike use of illegal and many prescription drugs, which are subject to extensive research attention, inappropriate (i.e., extra-medical and non-medical) use of NSAIDs has been less well investigated. This scoping review collates and describes what is known regarding non-medical and extramedical use of NSAIDs.

\section{Methods}

Scoping reviews are typically used where broader research questions exist and where research topics are under-documented in the literature [22-25]. They are used to identify gaps in knowledge; examine the extent (i.e. size), range (i.e. variety), and nature (i.e. characteristics) of the evidence on a certain topic or question (in this case, non-medical use of NSAIDs); collate findings from a wide range of sources; and make research and policy recommendations [22, 24, 26-28]. We adhered to Arksey and O'Malley's [22] five-stage iterative process scoping review methodology. These stages included the following: (1) identifying the essential research question, (2) identifying relevant studies, (3) selecting studies, (4) charting the data, and (5) collecting, summarising, and reporting the results. The review was underpinned by the research question, "What do we know about non-medical and extra-medical use of NSAIDs?" and collated and summarised all available published empirical and grey literature in the English language on this topic. No restriction was placed on date of publication or study type. The search was conducted in September 2020. The following databases were accessed: Web of Science, Cochrane Library, MEDLINE, PsycINFO, Social Science Citation Index, PubMed, Science Direct, and ResearchGate. The following key search terms informed the search strategy: aspirin, ibuprofen, ketoprofen, diclofenac, naproxen, celecoxib, indomethacin, loxoprofen, etoricoxib, mefenamic acid, and non-steroidal anti-inflammatory drugs (NSAIDs) in conjunction with abuse, misuse, off-label use, and non-medical use. Manual searching of reference lists was also undertaken.

Eligibility criteria focused on the non-medical use of NSAIDs. Inclusion and exclusion criteria were discussed and agreed with all members of the research team: records that referred to medical or prescribed use were excluded. The initial search identified 42,579 articles; following initial screening, 30,150 were removed for lack of relevance, with the remaining 12,429 screened for inclusion in the study. Finally, duplicates $(n=10,945)$ and further records that were not relevant were removed $(n=1416)$, leaving 72 records in total (Fig. 1). The 66 records were charted and thematically analysed, as per Arksey and O'Malley [22], by authors RB and MW. A table was created to chart relevant data (year of publication, author, location, method, key findings) and to analyse the extracted data thematically (Table 1). The textual dataset was re-read numerous times so researchers became familiar with the data and to identify and code emerging themes. Thematic manual coding then organised and subsequently structured the data into themes through patterns identified in associated categories (conducted by RB) [29]. Three themes emerged from the review: (1) indicative profile of people who engage in nonmedical or extra-medical use of NSAIDs; (2) antecedents for non-medical or extra-medical use; and (3) adverse health effects of non-medical and extra-medical use of NSAIDs.

\section{Results}

\subsection{Profile of Studies Reviewed}

In total, 72 studies were included in this scoping review (Table 1). The included records referred to a range of NSAID users (Table 2).

The findings from these 72 studies are presented under headings directly relating to the research question ("What do we know about non-medical use of NSAIDs?") and that emerged from the data analysis process: (1) indicative profile of people who engage in non-medical or extra-medical use of NSAIDs; (2) antecedents for non-medical or extramedical use; (3) adverse health effects of non-medical and extra-medical use of NSAIDs.

\subsection{Theme 1: Indicative Profile of People Who Engage in Non-Medical or Extra-Medical Use of Non-Steroidal Anti-Inflammatory Drugs (NSAIDs)}

\subsubsection{Non-Medical Use in Elite and Non-Elite Athletes}

Across the included records, excessive use of NSAIDs amongst elite and non-elite athletes was described as a 
Fig. 1 Flow diagram. NSAIDs non-steroidal anti-inflammatory drugs

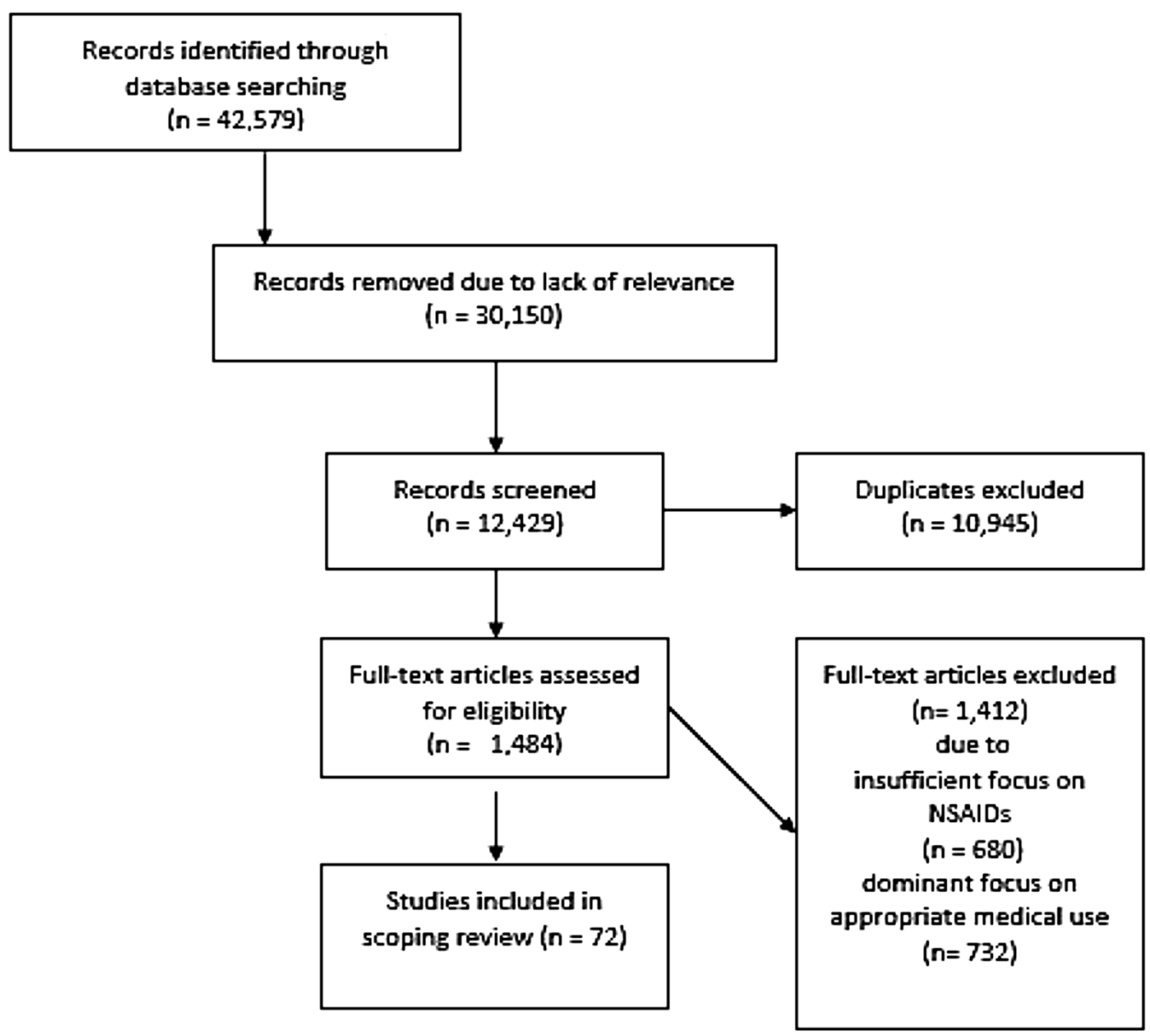

Table 1 Types of studies reviewed

\begin{tabular}{ll}
\hline Type of study & Number \\
\hline Experimental studies & 3 \\
Systematic literature review & 1 \\
Mixed-methods studies & 3 \\
Quantitative surveys & 19 \\
Observational study with follow-up quantitative survey & 1 \\
Quantitative cross-sectional evaluation using literacy and & 1 \\
$\quad$ numeracy instruments & \\
Quantitative evaluations of datasets containing information & 3 \\
$\quad$ on medical patients & 2 \\
Analyses of doping control forms & 1 \\
Analysis of drug-related overdose data & 2 \\
Content analysis of physician's records & 1 \\
Structured interview study based on DSM-IV-TR & 1 \\
Qualitative study & 13 \\
Clinical case reports/series & 1 \\
Scoping review & 10 \\
Narrative reviews & 4 \\
Editorials & 2 \\
Letters to the editor & 3 \\
Reports (including one online and one undergraduate) & 3 \\
Commentary & 1 \\
\hline
\end{tabular}

$D S M-I V-T R$ Diagnostic and Statistical Manual of Mental Disorders, Fourth Edition, Text Revision common practice. Although NSAIDs are not considered a performance-enhancing drug by the World Anti-Doping Agency [60], and evidence for their efficacy in exercise enhancement is limited [37], they may be considered a performance "enabling" drug in the athletic community because much of their use is centred on the prevention of pain during sporting events or training to enhance performance [14]. The evidence that this is effective is limited [6]. As an example, high levels of use of NSAIDs were documented during the 2014 FIFA (Fédération Internationale de Football Association) World Cup: 67\% of players took various types of medication during the tournament, most commonly NSAIDs. This was also noted in the 2010 [56], 2002 and 2006 [68] World Cups, as was the use of NSAIDs in wheelchair athletes in the Paralympics [65]. A Swiss narrative review referred to the use of NSAIDs in sport as "routine" and reported that over one-half of the professional football players reviewed in their study used NSAIDs. Additionally, up to one-third of all players used NSAIDs prior to every match, regardless of whether they played or not. Most athletes are unaware of the potentially dangerous effects of NSAIDs after strenuous exercise and rarely ask doctors for advice [15].

Survey data indicated high rates of use amongst athletes. A South African survey found that, despite negative 
Table 2 Typology of NSAID users

\begin{tabular}{ll}
\hline NSAIDs users & $\begin{array}{l}\text { Number } \\
\text { of stud- } \\
\text { ies }\end{array}$ \\
\hline Medical patients (including elderly patients and a person living with HIV) & 26 \\
Pharmacist patients & 10 \\
Elite and non-elite athletes/sports players & 15 \\
Members of the general population (including one study focusing on dental patients) & 15 \\
People who use anabolic androgenic steroids & 1 \\
Student population samples (two of which were student athletes) & 3 \\
Physiotherapist patients & 1 \\
People who use herbal products & 1 \\
\hline
\end{tabular}

NSAIDs non-steroidal anti-inflammatory drugs side effects experienced through taking NSAIDs, the prevalence of use in all runners was high, particularly during training and recovery, especially in ultramarathon runners [55]. Another study, conducted in France and focused on ultramarathon runners, found that almost $90 \%$ of participants were unaware of the dangers of such NSAID consumption and considered such use normal [43]. A US survey found that $75 \%$ of 681 student athletes had used NSAIDs in the previous 3 months, and 15\% were daily users [76]. An Irish survey found that over one-fifth of students $(n=149)$ surveyed exceeded the recommended dosage of NSAIDs, and poor knowledge of the side effects and dangers were noted [16]. A South African survey of triathletes found that 196 (59.9\%) participants reported using NSAIDs in the previous 3 months; of these, $25.5 \%$ $(n=50)$ consumed NSAIDs the day before the race, $17.9 \%$ $(n=35)$ consumed them immediately before the race and $47.4 \%(n=93)$ consumed them during the race. Of these, $48.5 \%(n=95)$ did not have a medical prescription [58].

An Italian study found that the most declared NSAIDs used by athletes were ibuprofen (13.8\%), diclofenac (12.7\%), aspirin (7.4\%), naproxen (6.9\%) and other NSAIDs such as propyphenazone [4]. An observational study undertaken in Switzerland of competitive mountain bikers, with a followup survey, found that $10 \%$ who finished the race consumed NSAIDs at least once during the competition day (immediately before, during or immediately after the race). A large majority $(79 \%)$ of them reported using only ibuprofen, two individuals reported using diclofenac and one individual reported using nimesulide. Diclofenac was used before and after the competition, whereas nimesulide was used during the competition [38]. Excessive dosages of NSAIDs were also noted in an Australian survey of physiotherapy patients [75].

\subsubsection{Non-and Extra-Medical Use in the General Population}

Evidence for non-medical use of NSAIDs dates back to 1966 in the literature [8], and a recent German study included NSAIDs in its analysis of harms associated with drugs with addictive potential [31]. This review found that the majority of NSAID use in the general population was unsupervised and therefore created an opportunity for overdose, despite high levels of awareness around the abuse potential of analgesics in general found in one study [70]. A mixed-methods study looking at excessive use and overdose in pharmacy recipients of OTC medicines found that a combination analgesic containing ibuprofen and codeine was one of the top three specific products most frequently associated with non-/extra-medical use [10], although this is likely to be attributable to the codeine ingredient. The majority of NSAID overdoses are asymptomatic, which poses a serious risk to people who use NSAIDs in higher doses or more frequently than recommended [35]. Use of NSAIDs for over 7 consecutive days and in doses larger than recommended (e.g. Davis and Robson [9]) was noted in the general population in the majority of the studies reviewed. Moreover, a survey in Jordan found that, where patients used NSAIDs under the supervision of a pharmacist, patients' awareness regarding safe use remained low, and the pharmacist's role in advising in this regard was said to be inadequately performed [17]. Of the total number of overdose cases studied in Northern Ireland, 6.8\% involved aspirin and 3.2\% involved ibuprofen, each either on its own or combined with other drugs [71].

A survey conducted in Yemen found that $57.7 \%$ of pharmacists suspected excessive NSAID use in their customers. Ketoprofen (an NSAID) was named amongst the drugs most commonly 'abused'. Most pharmacists (83.3\%) noticed an increase in such excessive use. Despite this knowledge, some pharmacists were afraid not to dispense the drugs because customers carried weapons [21]. These findings were supported in a qualitative study in the same region [36]. In Nigeria, $74 \%$ of a survey sample population sourced their NSAIDs from legitimate pharmaceutical outlets with poor dispensing practices. The majority (79\%) of these individuals had clinical conditions likely to be worsened by 
extra-medical NSAID use, whereas over $23 \%$ ingested more than two different NSAIDs at a time [66]. An Indian mixedmethods study found that $49 \%$ of patients did not follow the regimen and continued consuming NSAIDs of their own accord [50]. In Pakistan, use of NSAIDs without prescription was common, and a survey found that the most commonly used NSAID was mefenamic acid $(n=191$ [40.8\%]). Awareness around potential toxicity was very low [47].

A large number $(63 \%)$ of 1750 respondents in a US household survey reported NSAID use within the previous 12 months. NSAIDs were not well recognized by generic or brand names, and many respondents were unaware or unconcerned about potential harms. A total of $19 \%$ reported using more than the recommended dose, and $24 \%$ reported using multiple NSAIDs together at the same time. Overall, NSAID use appears to have increased in the USA since 2002 [48]. A US report found that, of 1326 people who used ibuprofen, $11 \%$ exceeded the daily limit and $4 \%$ exceeded the recommended maximum daily dose for other NSAIDs. Patients who have confidence in their own judgement of what correct dose to take have greater odds of exceeding the daily limit [20].

A Polish survey found that 57\% of OTC medicines bought by Polish consumers were analgesics, including NSAIDs. Although the majority of participants understood the harms of misusing NSAIDs, many disadvantageous behaviours were observed, such as not adhering to label instructions [45]. Another survey of university students conducted in Poland found that over $77 \%$ of the respondents confirmed that they used NSAIDs. Knowledge about the dangers associated with the use of NSAIDs was low. Use for longer periods of time than recommended was noted, and five individuals reported having a psychological dependence upon NSAIDs [52].

An Australian survey found that dental patients who used NSAIDs reported using ibuprofen (37\%), acetaminophen (27\%), acetaminophen/aspirin combination product (8\%), naproxen (8\%) and aspirin (4\%) [67].

Interestingly, abuse of topically applied NSAIDs emerged as a theme from a scoping review conducted in Jordan, including a case series of five males and six females with corneal melting associated with misuse and abuse of topical NSAIDs and three cases of corneal melting following topical use of NSAIDs [41].

An experimental study conducted in India also found that members of the general population may have been consuming NSAIDs unknowingly. This was discovered through the development of a liquid chromatography-mass spectrometry time-of-flight-based strategy to detect herbal products adulterated with steroids and NSAIDs. This was applied to 58 such products in India; ten were found to contain diclofenac as a synthetic adulterant, and all had been dispensed by practitioners of alternative medicines [63].

\subsubsection{Extra-Medical Use in Medical Patients}

In patients using NSAIDs that were legitimately prescribed for medical conditions, excessive or extra-medical use was also noted in many of the reviewed studies. One clinical case series in the USA documented five cases where pain had actually increased through overuse of NSAIDs and was alleviated when NSAID consumption was discontinued. The NSAIDs documented in these cases were ibuprofen, Naprosyn and Toradol [78]. Another clinical case series documented in Australia found that three patients of $27 \mathrm{had}$ hypokalaemia, and one patient required dialysis associated with use of high doses of NSAIDs such as ibuprofen [61].

Several clinical case presentations linked extra-medical use of NSAIDs with complications. In the USA, a 48-year-old previously healthy woman presented with medical diffuse myalgias and severe generalized weakness of all extremities and polyuria for a few weeks. The patient revealed that she had been taking about 20 tablets of ibuprofen daily for the last 3 months to control her ankle pain [11]. Also in the USA, a 58-year-old female living with HIV met DSM-V criteria for moderate substance use disorder with regards to NSAIDs [42]. In the UK, a 49-year-old man presented with epigastric discomfort, vomiting, lethargy and weakness. He denied use of the ibuprofen + codeine combination. Once discharged, he was subsequently resubmitted, once with a psychotic episode. The patient's general practitioner confirmed the abuse of the ibuprofen + codeine combination of at least 24 tablets on a number of occasions and a report of tablets concealed in an unmarked bottle at his bedside. Ibuprofen + codeine combination misuse was determined as the cause of his recurrent hypokalaemia episodes [73]. In Serbia, a 17-year-old male presented with moderate low back pain. Haematuria, eosinophilia and decreased creatinine clearance were detected and attributed to NSAID toxicity [39]. In Australia, a 39-year-old man presented after a 3 -day binge of ibuprofen + codeine combination tablets and caffeinated energy drink with profound hypokalaemia attributed to ibuprofen-mediated type 2 renal acidosis combined with the effects of caffeine [62].

Other types of studies confirmed extra-medical use amongst medical patients. A mixed-methods study of patients with chronic pain using an algorithm called the Abuse Index determined that, after 12 months, 2.5\% of people using NSAIDs were misusing. This meant that people were using more than prescribed and experiencing withdrawals and an inability to stop use [69]. A study based on DSM-IV-Text Revision (TR) criteria conducted in Germany with 400 patients found that $28(7 \%)$ fulfilled the criteria for non-opioid analgesic (including NSAIDs) dependence: 24 patients were currently dependent and four were in remission. All patients showed tolerance 
and/or withdrawal symptoms. NSAIDs were involved in the majority of cases $(n=25$ [89.3\%]) [33]. One Turkish study found that NSAID use was significant among patients with gastric perforation. Only nine of 60 (20.0\%) patients had sourced their NSAIDs through a prescription [34]. A Maiduguri survey found that several patients with peptic ulcer were using NSAIDs indiscriminately and lacked knowledge of their potential to worsen their health. The NSAIDs misused were ibuprofen (19.0\%), piroxicam (3.4\%), diclofenac $(14.8 \%)$, naproxen $(1.11 \%)$, acetylsalicylic acid (3.0\%) and ketoprofen (1.3\%) [19]. A similar finding was presented in a 2011 study of patients with chronic conditions contradictory to the use of NSAIDs who were using NSAIDs in a manner that might worsen their condition [59].

A narrative review conducted in the USA found that older adults were particularly at risk from harms caused by excessive use of NSAIDs because of underlying health conditions and larger repertoires of other prescribed medications. Many older patients did not adhere to the recommendations on the OTC medication labels. If misused, NSAIDs can cause congestive heart failure in older adults [18]. The risk of NSAID harm almost doubles with every decade of age after 55 years, and the majority of patients have painless bleeding. Ketorolac is said to present a higher risk than ibuprofen in older adults [40]. Of concern is that, according to a report in Manitoba, Canada, $75-80 \%$ of patients (approximately $16,500)$ received inappropriate and long-term NSAID prescriptions, particularly older adults, females, people living in rural areas and people with lower incomes [72].

\subsubsection{Non-Medical Use in People with Mental Health Issues/Problematic Use of Other Drugs}

We included some clinical case presentation data to suggest that people experiencing mental health issues or problematic use of other drugs may also be at risk of non-medical use of NSAIDs. In the UK, a 28-year-old female presented with weakness, vomiting and a history of mental health issues. Excessive dosing of NSAIDs was disclosed [74]. In France, a 17-year-old patient with a history of mental health issues presented with many ibuprofen-dependence symptoms. After being prescribed ibuprofen for pain, she progressively increased the dosage from $400 \mathrm{mg}$ four times daily to $400 \mathrm{mg}$ eight times daily. During the treatment, she developed withdrawal symptoms [51]. Additionally, in Australia, a 34-yearold woman in the third trimester of pregnancy presented with type 1 or distal renal tubular acidosis, acute-on-chronic renal dysfunction and hypokalaemia related to ibuprofen and codeine abuse. Some renal dysfunction continued after cessation of use and the delivery of the baby. Consensual urinary drug screening detected benzodiazepines, cannabis metabolites, amphetamine-like substances, methadone and opiates [57]. Most of the people who used analgesics studied in Yemen also used khat (Catha edulis Forsk.) [21, 36], a plant drug traditionally used by various peoples of the Horn of Africa, Yemen and the international diaspora populations of these cultures. It is considered a central nervous system (CNS)-stimulant drug as it contains phenylalkylamines (such as cathine, cathinone and norephedrine), which bear close structural resemblance to the neurotransmitters dopamine and norepinephrine and are of greatest importance to the stimulant activity of khat [81].

\subsection{Theme 2: Antecedents for Non-Medical or Extra-Medical Use}

In the reviewed studies that referred to the use of NSAIDs in the athletic community, motivators for use included the following: to mask symptoms that are a natural consequence of training adaptation, such as myalgia [44]; to prevent pain so exercise can continue $[6,30,38,44,60]$; to decrease pain, fatigue and cramping and improve performance [76]; to treat injuries $[38,58]$; to treat pain or swelling or to "play through" an injury [16, 38]; to obtain better relaxation and sleep after the race; and to reduce muscle inflammation or to treat a cold [38].

In medical patients, motivations or causal factors for extra-medical use documented included poor practitioner patient counselling, co-morbid diseases and lack of patient awareness of the impact of NSAID use in influencing the course of their disease progression [19]. This same study posited other contributory factors to extra-medical use of NSAIDs as including the unavailability of patients' medication records or poor retrieval systems and consulting multiple physicians, thereby increasing the chances for poly-pharmacy.

The reviewed studies indicated that, in the general population, non-medical use was motivated by achieving a euphoric state or 'high' [42, 51, 74, 79]; relieving tiredness, stress or discomfort; curing hangovers or replacing other medications [45]; and relieving headache, abdominal pains and pain associated with menstruation [52]. Limited health literacy is associated with misuse of OTC NSAIDs through lack of understanding of correct dosing and adverse health outcomes [32]. A US survey found that people with low levels of education were significantly less likely to use the NSAID safely or to seek medical assistance [1]. It has also been reported that many older patients also did not adhere to the recommendations on labels of the OTC medications [18]. 


\subsection{Theme 3: Adverse Health Effects of Non-Medical and Extra-Medical Use of NSAIDs}

Current evidence as collated by this review is that nonmedical and extra-medical use of NSAIDs poses significant health risks for individuals. A range of adverse health consequences were described, including nephrotoxicity (acute renal failure and acute interstitial nephritis) [74]; damage to the renal system; asthma exacerbation; gastrointestinal problems [14, 49, 60, 75]; hypertension and other cardiovascular diseases [38]; gastric erosions and ulceration; chronic gastritis; renal necrosis and disease; hepatocyte necrosis [54]; type 1 respiratory failure [5]; oliguria/anuria and gastric bleeds [15]; recurrent hypokalaemia episodes [57, 73]; withdrawal symptoms [51]; haematuria, eosinophilia and decreased creatinine clearance [39].

The majority of NSAID overdoses are asymptomatic, which poses a serious risk to people who use NSAIDs excessively without experiencing any noticeable adverse outcomes [35]. One example was found in a mixed-methods study in India, where, although $49 \%$ of patients did not follow the prescribed regimen, the majority of the adverse drug effects reported were mild to moderate in nature, with no serious reactions [50]. Moreover, a South African survey of triathletes found that the only symptoms reported were gastrointestinal [58]. This is despite evidence that NSAID use during athletic events poses major risks, including the development of renal complications and exercise-associated hyponatraemia. The South African National Kidney Foundation estimates that $10 \%$ of kidney failure is associated with NSAID overuse [55]. Of concern is a study in Jordan which found that the highest incidence of drug overdoses was in children 5 years old and younger [46].

NSAIDs pose a particular risk to older adults and can cause congestive heart failure if misused [18]. All NSAIDs increase the risk of gastrointestinal bleeding, myocardial infarction and stroke in patients aged $>65$ years [9]. One of the side effects reported with the chronic use of analgesics, including NSAIDs is the development of analgesic headache or, as it is sometimes called, analgesic overuse headache $[53,77]$. The mechanism of analgesic overuse headache is still unknown. However, some authors have suggested an inter-dose withdrawal phenomenon $[80,82]$ or increase in serotonin levels and upregulation of serotonin receptors in the frontal cortex, which subsequently increase sensitivity to pain [77].

\section{Discussion}

To our knowledge, this is the first large-scale mapping exercise to determine the nature and extent of research on nonmedical and extra-medical use of NSAIDs. The countries profiled were widespread and included France, the USA, South Africa, Netherlands, Australia, Canada, Greece, Germany, Turkey, Yemen, Spain, Switzerland, Serbia, Ireland, Jordan, Poland, Amman, Pakistan, the UK, Nigeria, Italy, India and Northern Ireland. The accumulated evidence across the reviewed studies suggests non-/extra-medical use of NSAIDs has increased over time.

There is a substantial body of literature related to the non-medical and extra-medical use of NSAIDs in athletic populations. In total, 14 studies were relevant to NSAID use in a wide range of athletes, including mountain bikers [38], student athletes [16, 76], endurance runners [43, 55], elite and non-elite athletes [14, 15, 58, 64], recreational runners [83] and elite footballers [6, 44], in addition to people identified as using anabolic androgenic steroids [4]. Overall, these studies reveal common and at times systematic use, with usage above the recommended dose not unusual and ibuprofen the NSAID used most frequently. For instance, in a study of 149 Irish student athletes, 94\% reported using NSAIDs in the past, with $63.8 \%$ previously using them before or after competition and/or practice; $13.9 \%$ took more than the recommended dosage, and this was higher (22.9\%) for OTC NSAIDs. Similar findings have been reported in professional football, with NSAIDs being the most used medication at the 2014 World Cup, with $54.2 \%$ of all players using them. Thus, the high prevalence of use seems to span both team and individual sports at both amateur and professional levels.

The reviewed studies also provide insight into the dominant motivations for NSAID use in athletic populations. Whilst these predominantly centre on pain management, various approaches to pain management are apparent. Specifically, some athletes use NSAIDs in response to an injury, others use them to manage pain from an existing injury and others use them as a prophylactic against anticipated pain or discomfort $[6,14,43,60]$. Thus, whilst NSAID use to manage or in response to injury may be considered performance-enabling motivations, use to offset anticipated pain or discomfort represents a performance-enhancing motivation. Prophylactic use of NSAIDs appears to be common in team $[6,84]$ and endurance $[55,83,85]$ sports. For teamsport athletes, frequent users of NSAIDs do so because they believe they facilitate performance by blocking pain before it occurs. For endurance athletes, there is an apparent belief that using NSAIDs can enhance performance by allowing a higher intensity to be achieved without experiencing greater discomfort, or the same intensity can be maintained with reduced discomfort. Such use is in spite of the limited evidence for the efficacy of NSAIDs to help manage pain prophylactically [86]; therefore, no clear justification exists for such use [15].

There is also evidence for a lack of awareness and/ or understanding of the risk of deleterious health effects 
stemming from NSAID use in athletic populations that may help explain the patterns of NSAID use reported. Such risks include gastric and renal side effects [86], as well as facilitating the development of exercise-associated hyponatremia [87]. For instance, poor knowledge of the side effects and dangers associated with NSAID use have been identified in student athletes [16], endurance runners [43, 85], professional footballers [15] and recreational runners [83]. Another possible explanation stems from the incremental model of doping behaviour and relates to the motivation to enhance performance [79]. This model describes a sequence of behavioural adaptations that occurs in response to the increasing demands of sport as one progresses from recreational sport towards elite competition. These adaptations advance from taking conscious control over one's diet and lifestyle through to use of prohibited substances and methods (i.e. doping). Interestingly, the use of prescribed and OTC medications is included in the model, being situated immediately prior to doping in the sequence of behavioural adaptations. Thus, the frequent reporting of prophylactic use of NSAIDs in the current review offers some support for athletes adopting NSAID use as a way to cope with the demands of high-level competitive sport. The limited understanding and awareness of possible harmful health effects of NSAID use seen in many athletes could potentially increase the likelihood of athletes adopting such strategies.

Similarly, amongst sections of the general population, there is a distinct lack of appreciation of the potential deleterious effects of NSAIDs. NSAIDs are ubiquitous within society, with their ease of availability influencing the commonly held belief that they are intrinsically benign. There is some evidence that the lack of knowledge amongst those engaging in inadvertent extra-medical use of NSAIDs may, at least in part, be attributed to a lack of effective communication by some health professionals [17, 21, 75]. However, inappropriate use of NSAIDs within the general population appears commonplace regardless of healthcare system, geographical region or level of national income. The drugs of use vary according to the specific licensing of products and their availability. However, all countries that have been studied have a high level of commonality. A key feature of extra-medical use of NSAIDs is the fact that acute overdose is often asymptomatic, reinforcing the belief that the effects are harmless regardless of dosage or frequency of self-administration. This may influence the individual, leading to the chronic, repeated extra-medical use with the potential for damage to multiple organs and systems.

The issues related to the inappropriate use of NSAIDs are not restricted to one section of the population. However, high levels within older populations raise specific concerns regarding the impact of high dosages and prolonged use of NSAIDs within the elderly. Older populations are potentially more vulnerable to the adverse effects of these drugs, with risks of untoward consequences being much higher amongst those whose NSAID use may be just one of a cocktail of prescribed drugs and OTC preparations [33]. Younger people have also been highlighted as an at-risk population, with high levels of use amongst students identified [16, 52].

While the predominant reasons for extra-medical use of NSAIDs within sports participants may be classified as the management of inflammation and pain, either prophylactically or in the treatment of actual pain, the rationale for use outside the sporting arena is less clear. Examples exist of rationales supporting the use of NSAIDs, for example, the management of adverse effects associated with prolonged and regular use of khat [21]. However, the motivation(s) for many users of NSAIDs is not understood. Wójta-Kempa and Krzyżanowski [45] included explanations of extra-medical use in terms of relieving stress, tiredness and discomfort, highlighting the need for improved education, particularly for those with low health literacy [32]. Further evidence of this need for improved education of the general population and training for health practitioners in delivering effective advice regarding NSAIDs can be seen in research from the USA [48]. Results showed high levels of use of multiple concomitant NSAIDs and commonly held beliefs that higher doses were more effective. Overall, appreciation of the potential adverse consequences of high dosages and/or prolonged use of these drugs is low, and understanding of how NSAIDs should be used effectively, in relation to both the frequency of use and the maximum dosage, is missing.

A common feature across many of the studies was the widely held belief that because a product can be obtained without a prescription and purchased OTC, it does not pose any significant threat to health. Therefore, there is no necessity to read the accompanying safety leaflet, and the drug's administration in relation to both dosage and frequency is at the discretion of the individual. There is a clear need to change this mindset within sections of the population and to alter the beliefs about and attitudes towards OTC medications.

\subsection{Limitations}

The current review was conducted within the scoping review framework so is limited to a broad summary of the key areas of research relevant to non-medical and extramedical use of NSAIDs. As such, it was beyond the scope of this work to provide specific insight into any one aspect of the extant literature on this topic. This also means we did not include an assessment of bias or the quality of the studies within our review. Future researchers may conduct one or more systematic reviews to address such issues. Also, as our review was limited to 'English language only' 
searches, it is possible we missed some relevant studies published in non-English outlets. It may be worthwhile in the future trying to identify relevant non-English publications that can add further to our understanding of this topic.

\section{Conclusion}

To our knowledge, this is the first large-scale mapping exercise to determine the nature and extent of research on non-medical and extra-medical use of NSAIDs. Emergent themes indicate a need for enhanced patient education, including among sports people; pharmacovigilance in terms of clinician recognition of aberrance; and prescriber and pharmacist awareness of the potential for extra-medical use and the related health harms.

\section{Declarations}

Funding No sources of funding were used to conduct this study or prepare this manuscript.

Conflict of interest Rebekah Brennan, Mayyada Wazaify, Haneen Shawabkeh, Ian Boardley, Jim McVeigh, and Marie Claire Van Hout have no conflicts of interest that are directly relevant to the content of this article.

\section{Ethics approval Not applicable.}

Consent to participate Not applicable.

Availability of data and material Data sharing is not applicable to this article as no datasets were generated or analysed during the current study.

Author Contributions All authors contributed to the conception and planning of the work, analysis and interpretation of the data, and drafting the manuscript. All authors read and approved the final version.

Open Access This article is licensed under a Creative Commons Attribution-NonCommercial 4.0 International License, which permits any non-commercial use, sharing, adaptation, distribution and reproduction in any medium or format, as long as you give appropriate credit to the original author(s) and the source, provide a link to the Creative Commons licence, and indicate if changes were made. The images or other third party material in this article are included in the article's Creative Commons licence, unless indicated otherwise in a credit line to the material. If material is not included in the article's Creative Commons licence and your intended use is not permitted by statutory regulation or exceeds the permitted use, you will need to obtain permission directly from the copyright holder. To view a copy of this licence, visit http://creativecommons.org/licenses/by-nc/4.0/.

\section{References}

1. Mullan J, Weston KMBA, Burns P, Mullan J, Rudd R. Consumer knowledge about over-the-counter NSAIDs: they don't know what they don't know. Aust New Zealand J Public Health. 2017;41(2):210. https://doi.org/10.1111/1753-6405.12589.

2. Fortune Business Insights. NSAIDs Market to Reach USD 24.35 Billion by 2027; Surging Research on Selective Cyclooxygenase-2 Inhibitors to Boost Growth. 2020. https://www. globenewswire.com/news-release/2020/05/28/2040374/0/en/ NSAIDs-Market-to-Reach-USD-24-35-Billion-by-2027-Surgi ng-Research-on-Selective-Cyclooxygenase-2-Inhibitors-toBoost-Growth-Fortune-Business-Insights.html\#: :text=Filin gs\%20Media\%20Partners-,NSAIDs\%20Market\%20to\%20Rea ch $\% 20$ USD $\% 2024.35 \% 20$ Billion $\% 20$ by $\% 202027 \% 3 \mathrm{~B} \% 20$ Sur ging,Growth $\% 3 \mathrm{~A} \% 20$ Fortune $\% 20 \mathrm{Business} \% 20$ Insights $\%$ E2\% 84\%A2. Accessed 13 Oct 2020.

3. Negm AA, Furst DE. Nonsteroidal anti-inflammatory drugs, disease-modifying antirheumatic drugs, nonopioid analgesics, $\&$ drugs used in Gout. In: Katzung BG, editor. Basic and Clinical Pharmacology. 14th ed. New York: McGraw-Hill; 2017.

4. Mazzarino M, Braganò MC, Donati F, de la Torre X, Botrè F. Effects of propyphenazone and other non-steroidal anti-inflammatory agents on the synthetic and endogenous androgenic anabolic steroids urinary excretion and/or instrumental detection. Anal Chim Acta. 2010;657(1):60-8. https://doi.org/10.1016/j. aca.2009.10.022.

5. Prower E, Hasnain O, Oscier C. H1N1 pneumonitis associated with long-term non-steroidal anti-inflammatory drug abuse. BMJ case rep. 2015;1:3. https://doi.org/10.1136/bcr-2014-205237.

6. Vaso M, Weber A, Tscholl PM, Junge A, Dvorak J. Use and abuse of medication during 2014 FIFA World Cup Brazil: a retrospective survey. BMJ Open. 2015;5(9):007608. https://doi. org/10.1136/bmjopen-2015-007608.

7. Murray RM. Minor analgesic abuse: the slow recognition of a public health problem. Br J Addict. 1980;75(1):9-17. https:// doi.org/10.1111/j.1360-0443.1980.tb00189.x.

8. Madden JS, Wilson CW. Deliberate aspirin intoxication. Br Med J. 1966;1(5495):1090.

9. Davis A, Robson J. The dangers of NSAIDs: look both ways. Br J Gen Pract. 2016;66(645):172-3. https://doi.org/10.3399/bjgp1 6 X684433.

10. Wazaify M, Hughes CM, McElnay JC. The implementation of a harm minimisation model for the identification and treatment of over-the-counter drug misuse and abuse in community pharmacies in Northern Ireland. Patient Educ Couns. 2006;64(13):136-41. https://doi.org/10.1016/j.pec.2005.12.008.

11. Patil S, Subramany S, Patil S, Gurram P, Singh M, Krause M. Ibuprofen abuse-A case of rhabdomyolysis, hypokalemia, and hypophosphatemia with drug-induced mixed renal tubular acidosis. Kidney Int Rep. 2018;3(5):1237-8. https://doi.org/10. 1016/j.ekir.2018.05.014.

12. Wills S. Over-the-counter products. In: Wills S, editor. Drugs of abuse. London: The Pharmaceutical Press; 1997. p. 131-43.

13. McKay FH. Evaluating mobile phone applications for health behaviour change: a systematic review. J Telemed Telecare. 2018;24(1):22. https://doi.org/10.1177/1357633X16673538.

14. Warden SJ. Prophylactic misuse and recommended use of nonsteroidal anti-inflammatory drugs by athletes. Br J Sports Med. 2009;43(8):548-9. https://doi.org/10.1136/bjsm.2008.056697.

15. Tscholl PM, Vaso M, Weber A, Dvorak J. High prevalence of medication use in professional football tournaments including the World Cups between 2002 and 2014: a narrative review with a focus on NSAIDs. Br J Sports Med. 2015;49(9):580-2. https:// doi.org/10.1136/bjsports-2015-094784.

16. O'Connor S, McCaffrey N, Whyte E, Moran K, Lacey P. Nonsteroidal anti-inflammatory drug use, knowledge, and behaviors around their use and misuse in Irish collegiate student-athletes. Phys Sportsmed. 2018;47(3):318-22. https://doi.org/10.1080/ 00913847.2018.1553468. 
17. Albsoul-Younes AM, Jabateh SK, Abdel-Hafiz SM, Al-Safi SA. Awareness and frequency of potential side effects on nonsteroidal anti-inflammatory drugs among the Jordanian patient population. Saudi Med J. 2004;25(7):907-11.

18. Roumie CL, Griffin MR. Over-the-counter analgesics in older adults: a call for improved labelling and consumer education. Drugs Aging. 2004;21(8):485-98. https://doi.org/10.2165/00002 512-200421080-00001.

19. Ohieku J, Jasini T. Non-steroidal anti-inflammatory drugs misuse among newly diagnosed and resurged peptic ulcer patients in Maiduguri-city. Nigeria JAMPS. 2015;4:1-10. https://doi.org/10. 9734/JAMPS/2015/19213.

20. Williams RA. What patients don't know about NSAIDs may lead to misuse. Pharm Today (Thorofare, NJ). 2018;24(5):34. https:// doi.org/10.1016/j.ptdy.2018.04.020.

21. Abood EA, Wazaify M. Abuse and misuse of prescription and nonprescription drugs from community pharmacies in Aden cityYemen. Subst Use Misuse. 2016;51(7):942-7. https://doi.org/10. 3109/10826084.2016.1155619.

22. Arksey H, O'Malley L. Scoping studies: towards a methodological framework. Int J Soc Res Methodol. 2005;8(1):19-32. https://doi. org/10.1080/1364557032000119616.

23. Khalil H, Peters M, Godfrey CM, McInerney P, Soares CB, Parker D. An evidence-based approach to scoping reviews. Worldviews Evid Based Nurs. 2016;13(2):118-23. https://doi.org/10.1111/ wvn. 12144.

24. Levac D, Colquhoun H, O'Brien KK. Scoping studies: advancing the methodology. Implement Sci. 2010;5(1):69. https://doi.org/10. 1186/1748-5908-5-69.

25. Peters MDJ, Godfrey CM, Khalil H, McInerney P, Parker D, Soares CB. Guidance for conducting systematic scoping reviews. Int J Evid Based Healthc. 2015;13(3):141-6. https://doi.org/10. 1097/xeb.0000000000000050.

26. Brandt SD, King LA, Evans-Brown M. The new drug phenomenon. Drug Test Anal. 2014;6(7-8):587-97. https://doi.org/10. 1002/dta.1686.

27. Daudt HML, van Mossel C, Scott SJ. Enhancing the scoping study methodology: a large, inter-professional team's experience with Arksey and O'Malley's framework. BMC Med Res Methodol. 2013;13(1):48. https://doi.org/10.1186/1471-2288-13-48.

28. Tricco AC, Lillie E, Zarin W, O'Brien K, Colquhoun H, Kastner $\mathrm{M}$, et al. A scoping review on the conduct and reporting of scoping reviews. BMC Med Res Methodol. 2016;16:15. https://doi. org/10.1186/s12874-016-0116-4

29. Crossley M. Narrative Analysis. In: Lyons E, Coyle A, editors. Analysing qualitative data in psychology. London: SAGE Publications, Ltd; 2007. p. 131-144.

30. Cornu C, Grange C, Regalin A, Munier J, Ounissi S, Reynaud $\mathrm{N}$, et al. Effect of non-steroidal anti-inflammatory drugs on sport performance indices in healthy people: a meta-analysis of randomized controlled trials. Sports Med Open. 2020;6(1):20. https:// doi.org/10.1186/s40798-020-00247-w.

31. Bonnet U, Specka M, Soyka M, Alberti T, Bender S, Grigoleit $\mathrm{T}$, et al. Ranking the harm of psychoactive drugs including prescription analgesics to users and others-a perspective of german addiction medicine experts. Front Psychiatry. 2020. https://doi. org/10.3389/fpsyt.2020.592199.

32. Jang SM, Jiang R, Grabe D, Barton A. Assessment of literacy and numeracy skills related to non-steroidal anti-inflammatory drug labels. SAGE Open Med. 2019;7:2050312119834119. https://doi. org/10.1177/2050312119834119.

33. Bonnet U, Strasser JC, Scherbaum N. Screening for physical and behavioral dependence on non-opioid analgesics in a German elderly hospital population. Addict Behav. 2019;90:265-71. https://doi.org/10.1016/j.addbeh.2018.11.009.
34. Egwuonwu O, Chinedu O, Chianakwana G, Anyanwu S, Emegoakor C, Nzeako H. Changing pattern of perforated PUD: Are NSAIDs to be blamed? Turk J Surg. 2019;35(2):105-10. https:// doi.org/10.5578/turkjsurg.4145.

35. Hudson S. The Misuse of Over-the-Counter NSAIDs. BU Well. 2019;4(1)

36. Abood EA, Scott J, Wazaify M. User experiences of prescription and over-the-counter drug abuse in Aden City, Yemen. Pharm (Basel). 2018. https://doi.org/10.3390/pharmacy6030099.

37. Holgado D, Hopker J, Sanabria D, Zabala M. Analgesics and sport performance: beyond the pain-modulating effects. PMR. 2018;10(1):72-82. https://doi.org/10.1016/j.pmrj.2017.07.068.

38. Chlíbková D, Ronzhina M, Nikolaidis PT, Rosemann T, Knechtle B. Non-steroidal anti-inflammatory drug consumption in a multi-stage and a 24-h mountain bike competition. Front Physiol. 2018;9:1272. https://doi.org/10.3389/fphys.2018.01272.

39. Jovičić J, Brkj T, Terzi B, Gvozdi B, Antonijevj V, Petrovi D, et al. Chronic non malignant pain and nonsteroid antinflammatory drugs misuse: Nsaid misuse. Serb J Anesth Intensive Ther. 2018:40:117-23.

40. Pourmand A, Jasani G, Shay C, Mazer-Amirshahi M. The evolving landscape of acute pain management in the era of the opioid crisis. Curr Pain Headache Rep. 2018;22(11):73. https://doi.org/ 10.1007/s11916-018-0728-y.

41. Al-Khalaileh W, Wazaify M, Van Hout MC. The misuse and abuse of ophthalmic preparations: a scoping review of clinical case presentations and extant literature. Int J Ment Health Addict. 2018;16(4):1055-84. https://doi.org/10.1007/s11469-017-9868-2.

42. Godersky ME, Vercammen LK, Ventura AS, Walley AY, Saitz R. Identification of non-steroidal anti-inflammatory drug use disorder: a case report. Addict Behav. 2017;70:61-4. https://doi.org/ 10.1016/j.addbeh.2017.02.008.

43. Didier S, Vauthier JC, Gambier N, Renaud P, Chenuel B, Poussel M. Substance use and misuse in a mountain ultramarathon: new insight into ultrarunners population? Res Sports Med. 2017;25(2):244-51. https://doi.org/10.1080/15438627.2017. 1282356.

44. Tscholl P, Gard S, Schindler M. A sensible approach to the use of NSAIDs in sports medicine. SEMS. 2016;65:15-20. https://doi. org/10.34045/SSEM/2017/8.

45. Wójta-Kempa M, Krzyżanowski DM. Correlates of abusing and misusing over-the-counter pain relievers among adult population of Wrocław (Poland). Adv Clin Exp Med. 2016;25(2):349-60. https://doi.org/10.17219/acem/58887.

46. Kalbani RJ, Wazaify M. Prevalence of prescription and nonprescription drugs-related overdoses at emergency departments in Amman-a cross sectional study. J Substance Use. 2016;22(1):77-82. https://doi.org/10.3109/14659891.2016.11448 03.

47. Zamir Q, Nadeem A. Non-steroidal anti-inflammatory drugs vs. Paracetamol: drug availability, patients' preference and knowledge of toxicity. J Ayub Med Coll Abbottabad. 2016;28(4):746-9.

48. Cryer B, Barnett MA, Wagner J, Wilcox CM. Overuse and misperceptions of nonsteroidal anti-inflammatory drugs in the United States. Am J Med Sci. 2016;352(5):472-80. https://doi.org/10. 1016/j.amjms.2016.08.028.

49. Pulawski S. Study: Misuse of NSAIDs for chronic pain may be prevalent. OTE. 2015;18(6):57.

50. Bhalla V, Bajaj UM. Abuse and misuse potential of commonly used non-steroidal anti inflammatory drugs (NSAIDS) In Indian scenario, a Pharmacovigilance model study. AJPTI. 2014;2(07):38-42.

51. Etcheverrigaray F, Grall-Bronnec M, Blanchet MC, Jolliet P, Victorri-Vigneau C. Ibuprofen dependence: a case report. Pharmacopsychiatry. 2014;47(3):115-7. https://doi.org/10.1055/s0034-1371868. 
52. Wawryk-Gawda E, Chylinska-Wrzos P, Lis-Sochocka M, Jodlowska-Jedrych B. Consumption and awareness of students about nonsteroidal anti-inflammatory drugs. Curr Issues Pharm Medical Sci. 2014;27(3):175. https://doi.org/10.1515/ cipms-2015-0010.

53. Kristoffersen E, Lundqvist C. Medication-overuse headache: epidemiology, diagnosis and treatment. Ther Adv Drug Saf. 2014;5(2):87-99. https://doi.org/10.1177/2042098614522683.

54. Pilgrim JL, Dobbin M, Drummer OH. Fatal misuse of codeineibuprofen analgesics in Victoria, Australia. Med J Aust. 2013;199(5):329-31. https://doi.org/10.5694/mja12.11843.

55. Joslin J, Lloyd JB, Kotlyar T, Wojcik SM. NSAID and other analgesic use by endurance runners during training, competition and recovery. S Afr J Sports Med. 2013;25(4):101. https://doi.org/10. 17159/2078-516X/2013/v25i4a340.

56. Tscholl PM, Dvorak J. Abuse of medication during international football competition in 2010-lesson not learned. Br J Sports Med. 2012;46(16):1140. https://doi.org/10.1136/bjspo rts-2011-090806.

57. Mallett A, Lynch M, John GT, Healy H, Lust K. Ibuprofen-related renal tubular acidosis in pregnancy. Obstet Med. 2011;4(3):122-4. https://doi.org/10.1258/om.2011.110041.

58. Gorski T, Cadore EL, Pinto SS, da Silva EM, Correa CS, Beltrami FG, et al. Use of NSAIDs in triathletes: prevalence, level of awareness and reasons for use. Br J Sports Med. 2011;45(2):85-90. https://doi.org/10.1136/bjsm.2009.062166.

59. Adams RJ, Appleton SL, Gill TK, Taylor AW, Wilson DH, Hill CL. Cause for concern in the use of non-steroidal anti-inflammatory medications in the community-a population-based study. BMC Fam Pract. 2011;12(1):70. https://doi.org/10.1186/ 1471-2296-12-70.

60. Warden SJ. Prophylactic use of NSAIDs by athletes: a risk/benefit assessment. Phys Sportsmed. 2010;38(1):132-8. https://doi.org/ 10.3810/psm.2010.04.1770.

61. Frei MY, Nielsen S, Dobbin MDH, Tobin CL. Serious morbidity associated with misuse of over-the-counter codeine-ibuprofen analgesics: a series of 27 cases. Med J Aust. 2010;193(5):294-6. https://doi.org/10.5694/j.1326-5377.2010.tb03911.x.

62. Ernest D, Chia M, Corallo CE. Profound hypokalaemia due to Nurofen Plus and Red Bull misuse. Crit Care Resusc. 2010;12(2):109-10.

63. Savaliya AA, Prasad B, Raijada DK, Singh S. Detection and characterization of synthetic steroidal and non-steroidal anti-inflammatory drugs in Indian ayurvedic/herbal products using LC-MS/ TOF. Drug Test Anal. 2009;1(8):372-81. https://doi.org/10.1002/ dta.75.

64. Tscholl PM, Feddermann N, Junge A, Dvorak J. The use and abuse of painkillers in international soccer: data from 6 FIFA tournaments for female and youth players. Am J Sports Med. 2009;37(2):260-5. https://doi.org/10.1177/0363546508324307.

65. Tsitsimpikou C, Jamurtas A, Fitch K, Papalexis PT. K Medication use by athletes during the Athens 2004 Paralympic Games. Br J Sports Med. 2009;43(14):1062-7. https://doi.org/10.1136/bjsm. 2009.062521.

66. Awofisayo OS, Awofisayo OA, Iferi II, Akpan OE. The pattern of sale and use of non-steroidal anti-inflammatory drugs in rural and urban centres in Nigeria. Trop J Pharm Res. 2009. https://doi.org/ 10.4314/tjpr.v7i3.14685.

67. Heard KJ, Ries NL, Dart RC, Bogdan GM, Zallen RD, Daly F. Overuse of non-prescription analgesics by dental clinic patients. BMC Oral Health. 2008;8(1):33. https://doi.org/10.1186/ 1472-6831-8-33.

68. Tscholl PM, Junge A, Dvorak J. The use of medication and nutritional supplements during FIFA World Cups 2002 and 2006. Br
J Sports Med. 2008;42(9):725-30. https://doi.org/10.1136/bjsm. 2007.045187.

69. Adams EH, Breiner S, Cicero TJ, Geller A, Inciardi JA, Schnoll SH, et al. A Comparison of the Abuse Liability of Tramadol, NSAIDs, and Hydrocodone in Patients with Chronic Pain. J Pain Symptom Manage. 2006;31(5):465-76. https://doi.org/10.1016/j. jpainsymman.2005.10.006.

70. Wazaify M, Shields E, Hughes CM, McElnay JC. Societal perspectives on over-the-counter (OTC) medicines. Fam Pract. 2005;22(2):170-6. https://doi.org/10.1093/fampra/cmh723.

71. Wazaify M, Kennedy S, Hughes CM, McElnay JC. Prevalence of over-the-counter drug-related overdoses at Accident and Emergency departments in Northern Ireland-a retrospective evaluation. J Clin Pharm Ther. 2005;30(1):39-44. https://doi.org/10.1111/j. 1365-2710.2004.00607.x.

72. Hodges D. Patients at risk from misuse of NSAIDs in Manitoba. Medical Post. 2004;40(11): 16.

73. Dyer BT, Martin JL, Mitchell JL, Sauven NC, Gazzard B. Hypokalaemia in ibuprofen and codeine phosphate abuse. Int $\mathbf{J}$ Clin Pract. 2004;58(11):1061-2. https://doi.org/10.1111/j.13685031.2004.00304.x.

74. Chetty R, Baoku Y, Mildner R, Banerjee A, Vallance D, Haddon A, et al. Severe hypokalaemia and weakness due to Nurofen misuse. Ann Clin Biochem. 2003;40(Pt 4):422-3. https://doi.org/10. 1258/000456303766477101.

75. Grimmer K, Kumar S, Gilbert A, Milanese S. Non-steroidal antiinflammatory drugs (NSAIDs): physiotherapists' use, knowledge and attitudes. Aust J Physiother. 2002;48(2):82-92. https://doi. org/10.1016/s0004-9514(14)60202-6.

76. Warner DC, Schnepf G, Barrett MS, Dian D, Swigonski NL. Prevalence, attitudes, and behaviors related to the use of nonsteroidal anti-inflammatory drugs (NSAIDs) in student athletes. J Adolesc Health. 2002;30(3):150-3. https://doi.org/10.1016/s1054139x(01)00325-1.

77. Srikiatkhachorn A, Tarasub N, Govitrapong P. Effect of chronic analgesic exposure on the central serotonin system: a possible mechanism of analgesic abuse headache. Headache. 2000;40(5):343-50. https://doi.org/10.1046/j.1526-4610.2000. 00052.x.

78. Nakahura T, Griswold W, Lemire J, Mendoza S, Reznik V. Nonsteroidal anti-inflammatory drug use in adolescence. J Adolesc Health. 1998;23(5):307-10. https://doi.org/10.1016/s1054$139 x(98) 00036-6$.

79. Abbott FV, Fraser MI. Use and abuse of over-the-counter analgesic agents. J Psychiatry Neurosci. 1998;23(1):13-34.

80. Mathew N. Medication misuse headache. Cephalalgia. 1998;18(Suppl 21):34-6. https://doi.org/10.1177/0333102498 018 s2109.

81. Nichols T, Khondkar P, Gibbons S. The psychostimulant drug khat (Catha edulis): A mini-review. Phytochem Lett. 2015;13:127-33. https://doi.org/10.1016/j.phytol.2015.05.016.

82. Symon D. Twelve cases of analgesic headache. Arch Dis Child. 1998;78(6):555-6. https://doi.org/10.1136/adc.78.6.555.

83. Rosenbloom CJ, Morley FL, Ahmed I, Cox AR. Oral non-steroidal anti-inflammatory drug use in recreational runners participating in Parkrun UK: prevalence of use and awareness of risk. Int J Pharm Prac. 2020;28(6):561-9. https://doi.org/10.1111/ijpp.12646.

84. Holmes N, Cronholm PF, Duffy AJ III, Webner D. Nonsteroidal anti-inflammatory drug use in collegiate football players. Clin J Sport Med. 2013;23(4):283-7.

85. Whatmough S, Mears S, Kipps C. The use of non-steroidal antiinflammatories (NSAIDS) at the 2016 London Marathon. Br J Sports Med. 2017;51(4):409. https://doi.org/10.1136/bjsports2016-097372.317. 
86. Küster M, Renner B, Oppel P, Niederweis U, Brune K. Consumption of analgesics before a marathon and the incidence of cardiovascular, gastrointestinal and renal problems: a cohort study. BMJ Open. 2013;3(4):e002090. https://doi.org/10.1136/bmjop en-2012-002090.
87. Hew-Butler T, Rosner M, Fowkes-Godek S, Dugas J, Hoffman $\mathrm{M}$, Lewis D, et al. Statement of the Third International ExerciseAssociated Hyponatremia Consensus Development Conference, Carlsbad, California, 2015. Clin J Sport Med. 2015;25(4):303-21. 